\title{
ДОСЛІДЖЕННЯ ПРОДУКТИВНОСТІ ПРОЦЕСУ ЛАЗЕРНОГО СПЛАВЛЕННЯ ПОРОШКОВОГО МАТЕРІАЛУ МЕТОДОМ МАТЕМАТИЧНОЇ СТАТИСТИКИ
}

๑ П. В. Кондрашев, к.т.н., доцент, НТУУ «КПI», Украйна

Разработана методика повышения производительности процесса лазерного сплавления порошкового материала.

Сущность данной методики заключается в построении математической модели производительности в виде уравнения регрессии второго порядка и последующего анализа функции отклика. Расчет проводился с использованием методов математической статистики.

The technique of improving the performance of the process of laser fusion of the powder material. The essence of this method is to construct a mathematical model of performance in the form of a regression equation of the second order, and further analysis of the response function. The calculation was performed using the methods of mathematical statistics.

Постановка проблеми

Технологія «Rapid Prototyping», базовою складовою, якої $\epsilon$ процес лазерного сплавлення порошкового матеріалу, широко застосовується високорозвиненими країнами в усьому світі для безпосереднього виготовлення, наприклад штампів, прес-форм та ін. Наприклад, порівняно 3 традиційним надшвидкісним різанням, технологія «Rapid Prototyping», яка використовує в якості інструменту сфокусований лазерний промінь, дозволяє створювати вироби не тільки 3 металевих, а й з керамічних матеріалів. Не дивлячись на вражаючі успіхи в області розвитку лазерної техніки і технології, перед розробниками стоять питання підвищення продуктивності та якості виробів, виготовлених за допомогою швидкого прототипування.

\section{Аналіз попередніх досліджень \\ Враховуючи} високу складність протікання фізичних процесів, пов'язаних 3 реалізацією технології лазерного сплавлення порошкового матеріалу в даній роботі була використана активна стратегія проведення експерименту, яка дає можливість отримати більш достовірні результати експериментальних досліджень порівняно 3 пасивною стратегією. Аналіз літературних джерел [1-4] показав різну ступінь статистичної значимості кожного технологічного фактора, який впливає на продуктивність процесу лазерного сплавлення порошкового матеріалу. Зупинимося детальніше на декількох 3 них. Зміна положення підкладки 
відносно пристрою подачі порошкового матеріалу, впливає на зміну таких показників сплавленого компонента як, морфологічні властивості, внутрішня мікроструктура (порожні фрагменти, раковини, мікротріщини). Масова витрата порошкового матеріалу важливий фактор впливу на продуктивність процесу лазерного сплавлення порошкової композиції, але при збільшенні показників масової витрати прямо пропорційно потрібно збільшувати потужність лазерного випромінювання. Термодинамічні властивості порошкового матеріалу, такі як температура плавлення, залежать від потужності лазерного випромінювання, чим вище температура плавлення порошкового матеріалу, тим більша потужність необхідна для його ефективного сплавлення. Враховуючи ці обставини приймаємо, що серед базових, порошкових матеріалів, використовуваних для технології лазерного сплавлення, широке застосування отримали порошки на основі нікелю, титану, кобальту. Найбільш поширений з цієї групи порошок ПГСР-3 базовою складовою якого $€$ нікель, який має найменшу температуру плавлення $1453{ }^{\circ} \mathrm{C}$ [5], порівняно з титаном і кобальтом. Тип транспортуючого газу суттєво впливає на якість сплавлення порошкового матеріалу, тобто для більш ефективного сплавлення порошку транспортування дисперсної фази необхідно проводити в інертному середовищі, наприклад газ аргон, відзначено в роботах $[6,7]$. Це дає можливість попередити утворення оксидної плівки під час впливу лазерного випромінювання, яка має великий градієнт температури плавлення, але для цього необхідно спеціалізоване обладнання з можливістю постійної заправки досить дорогих інертних газів (аргон, гелій, неон). Тому, з точки зору економічної доцільності, експеримент проводився з використанням стислого повітря. Одним 3 головних факторів впливу на продуктивність і якість сплавлення порошкової композиції $€$ конфігурація пристрою подачі порошкового матеріалу (сопла різних конструкцій) [8, 9]. Таким чином, на підставі аналізу літературної інформації, основні технологічні фактори, що впливають на продуктивність процесу лазерного сплавлення порошкового матеріалу можна розділити на дві групи. Перша це фактори, значення яких необхідно зафіксувати в стабільному стані, до них відносяться довжина хвилі та потужність лазерного випромінювання, тип порошкової композиції, геометричні властивості порошку, тип транспортуючого газу. Фактори, яким необхідно задати певний інтервал варіювання - це конфігурація пристрою подачі та масова витрата порошкового матеріалу, швидкість переміщення підкладки, положення підкладки (на яку здійснюється 
процес лазерного сплавлення) відносно пристрою подачі порошкової композиції.

\section{Мета роботи}

Метою даної роботи є пошук рішень, спрямованих на підвищення продуктивності процесу лазерного сплавлення порошкової композиції ПГСР-3.

\section{Результати проведених досліджень}

Для дослідження продуктивності процесу лазерного сплавлення порошкового матеріалу ПГСР-3 був обраний не композиційний план Бокса-Бенкена для 4-х технологічних факторів, що має хороші статистичні характеристики та реалізується рівнянням регресії другого порядку [10].

$$
\begin{aligned}
& y=b_{0}+\sum_{i=1}^{i=k} b_{i} x_{i}+ \\
& +\sum_{i \leq 1}^{i=k} b_{i j} x_{i} x_{j}+\sum_{i=1}^{i=k} b_{i i} x_{i}^{2},
\end{aligned}
$$

де $\mathrm{k}$ - кількість технологічних факторів; $b_{0}, b_{i}, b_{i j}, b_{i i}-к о-$ ефіцієнти рівняння регресії; i, j - індекси.

Як функції відгуку була використана продуктивність (Т). В якості технологічних факторів впливу на продуктивність процесу лазерного сплавлення порошкової композиції (визначених раніше), за умови стабілізації факторів діаметра лазерного променя, щільності та потужності лазерного випромінювання були використані геометрія кутів утворюючих сопла $\left(x_{1}\right)$, масова витрата порошку $\left(x_{2}\right)$, швидкість переміщення підкладки $\left(x_{3}\right)$, положення під- кладки щодо зрізу сопла $\left(\mathrm{x}_{4}\right)$. Коефіцієнти рівняння регресії $\mathrm{b}_{0}, \mathrm{~b}_{\mathrm{i}}, \mathrm{b}_{\mathrm{ij}}, \mathrm{b}_{\mathrm{ii}}$-моделі (1) розраховувалися за допомогою спеціалізованого програмного забезпечення з використанням математичного апарату лінійної алгебри [10], залежність (2). Формування матриці умов експерименту $\mathrm{X}$ відбувалося з використанням збалансованої блок-схеми для 4-х незалежних змінних $\left(\mathrm{x}_{1}, \mathrm{x}_{2}, \mathrm{x}_{3}, \mathrm{x}_{4}\right)$, яка складається 3 6-ти блоків (повнофакторний експеримент ${ }^{2}$ ) [10], варіювання технологічних факторів проводилося на трьох рівнях (мінімум, центр, максимум).

$$
\mathrm{B}=\left(\mathrm{X}^{\top} \mathrm{X}\right)^{1}\left(\mathrm{X}^{\top} \mathrm{Y}\right)
$$

Перевірка гіпотези стосовно адекватності отриманої математичної моделі продуктивності процесу лазерного сплавлення порошкового матеріалу, проводилася з використанням критерію Фішера $F$ [10]. Достовірність результатів експерименту за даним критерієм відповідає 5 \%-й похибці (3).

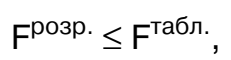

де $F^{\text {розр. }}$ - розрахункове значення критерію Фішеру [10];

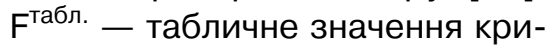
терію Фішеру [10].

Рівні варіювання технологічних факторів $\left(\mathrm{x}_{\mathrm{i}}\right)$ були визначені експериментально (табл.).

Проведена статистична обробка результатів експериментальних досліджень показала, що всі коефіцієнти рівняння регресії виявилися статистично значимими, для отриманої математичної моделі продуктив- 
Рівні варіювання технологічних факторів

\begin{tabular}{|c|c|c|c|c|}
\hline \multirow{2}{*}{$\begin{array}{c}\text { Рівні варіювання технологічних } \\
\text { факторів }\end{array}$} & \multicolumn{4}{|c|}{ Незалежні змінні } \\
\cline { 2 - 5 } & $x_{1}$ & $x_{2}$ & $x_{3}$ & $x_{4}$ \\
\hline Розмірність & град. & г/с & мм/с & мм \\
\hline Основний рівень & 40 & 0,3 & 2,0 & 5 \\
\hline Інтервал варіювання & 10 & 0,1 & 1,0 & 2 \\
\hline Верхній рівень & 50 & 0,4 & 3,0 & 7 \\
\hline Нижній рівень & 30 & 0,2 & 1,0 & 3 \\
\hline
\end{tabular}

ності процесу лазерного сплавлення порошкового матеріалу (Т) статистична гіпотеза про адекватність підтвердилася, рівняння регресії адекватне т.я., виконується умова (3). Для більш наочного уявлення про ступінь статистичної значимості кожного з технологічних факторів на продуктивність процесу лазерного сплавлення порошкового матеріалу ПГСР-3 була побудована рангова діаграма (рис. 1, а).

Як видно з рис. 1, а, найбільш суттєвий лінійний вплив на функцію відгуку має геометрія утворюючих сопла, швидкість переміщення і положення підкладки відносно зрізу сопла, фактори $\mathrm{x}_{1}, \mathrm{x}_{3}, \mathrm{x}_{4}$ коефіцієнти $\mathrm{b}_{1}$, $\mathrm{b}_{3}, \mathrm{~b}_{4}$ відповідно. Також слід зазначити суттєвий квадратичний вплив на відгук мають всі фактори $\mathrm{x}_{1}, \mathrm{x}_{2}, \mathrm{x}_{3}, \mathrm{x}_{4}$ коефіцієнти $\mathrm{b}_{11}$, $b_{22}, b_{33}, b_{44}$. Більш детальну картину зміни функції відгуку можна спостерігати, керуючись графічними залежностями, представленими на рис. 1, б і 2, а, б. Зменшення продуктивності (T) у загальному випадку до показника $0,7 \ldots 0,8$ мм $^{3} / \mathrm{c}$ (рис. 1, a, 2, a, б) відбувається за рахунок віддалення положення підклад- ки в обидва напрямки від «фокусу» газопорошкового струменя. Також важливий фактор зменшення продуктивності (Т) є геометрія кутів утворюючих сопла, так сопла з кутами $30^{\circ}$ i $50^{\circ}$ формують великі за розмірами площі поперечного перерізу газопорошкового струменя 3 низькими показниками дисперсної фази в зоні впливу лазерного випромінювання (рис. 1, б, 2, б). Збільшення продуктивності, діапазон 1,1... 1,3 мм³/с відбувається головним чином за рахунок розташування підкладки в «фокусі» газопорошкового струменя, сопло з геометрією кутів утворюючих $40^{\circ}$ (рис. 1, б, 2, б), в результаті чого в зоні лазерної обробки формується газопорошковий струмінь з високим вмістом дисперсної фази. Також слід зазначити, що максимальний показник продуктивності (Т) 1,3 мм $3 /$ с (рис. 1, б) спостерігається при наступних значеннях незалежних змінних, геометрія кутів утворюють сопел $40^{\circ}$, масова витрата порошкового матеріалу 0,2 г/с, швидкість переміщення підкладки 1 мм/с, положення підкладки щодо зрізу сопла 


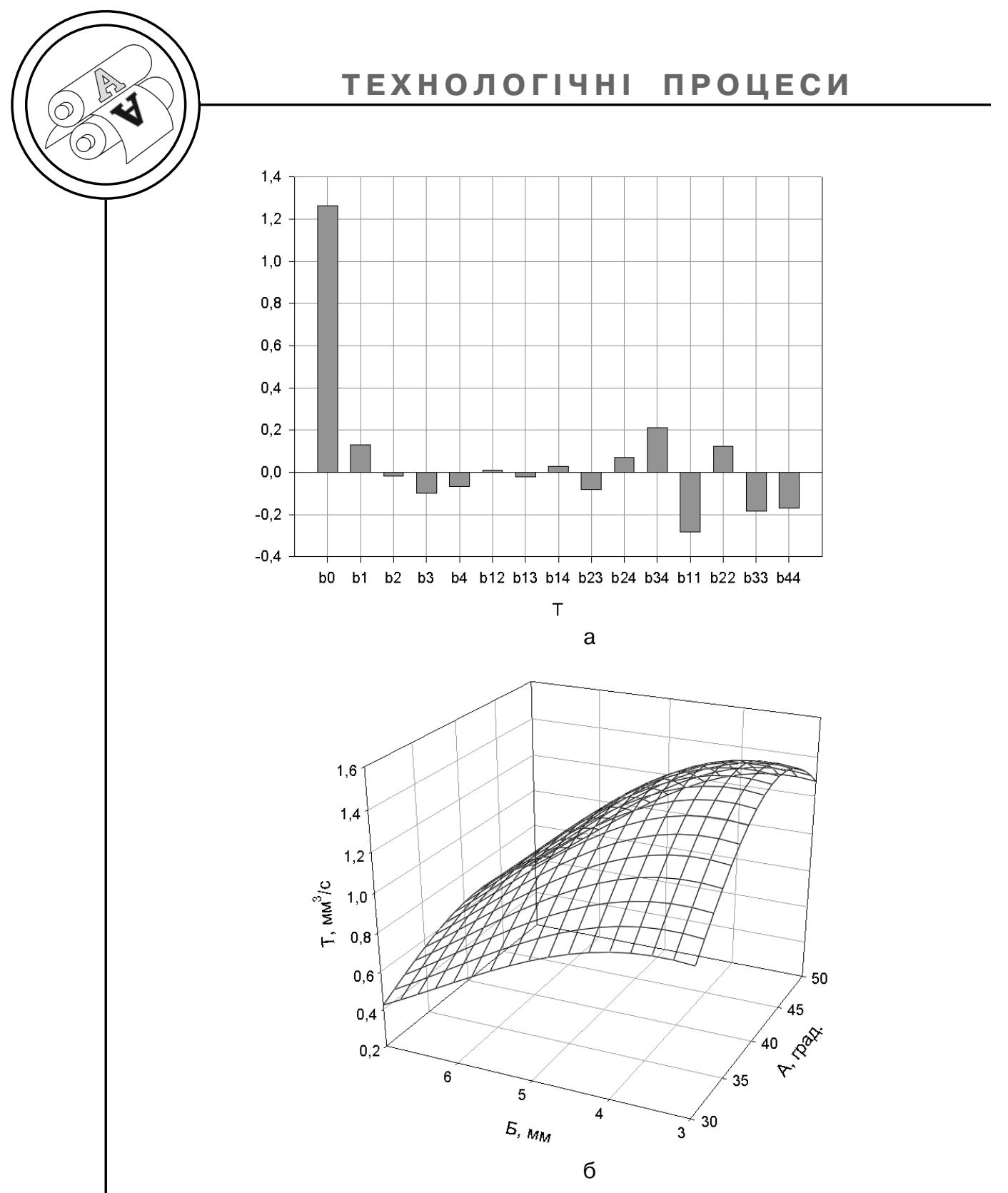

Рис. 1. Рангова діаграма ступеня статистичної значимості технологічних факторів на функцію відгуку (Т) (а) та залежність продуктивності сплавленого компонента (Т) від геометрії кутів утворюючих сопла (А) для різних положень підкладки (Б) з масовою витратою порошку 0,2 г/с та швидкістю переміщення підкладки $1 \mathrm{~mm} / \mathrm{c}$

5 мм (область «фокусу» газопорошкового струменя), це пояснюється великим вмістом дисперсної фази в зоні сфокусованого лазерного випромінювання. Мінімальний показник продуктивності $\left(\right.$ (Т) $0,2 \quad \mathrm{~mm}^{3} / \mathrm{c}$ (рис. 2, б) отриманий при наступних показниках технологічних факторів геометрія кутів утворюють сопел $30^{\circ}$, масова витрата порошкового матеріалу 0,4 г/с, швидкість переміщення підкладки 3 мм/с, 

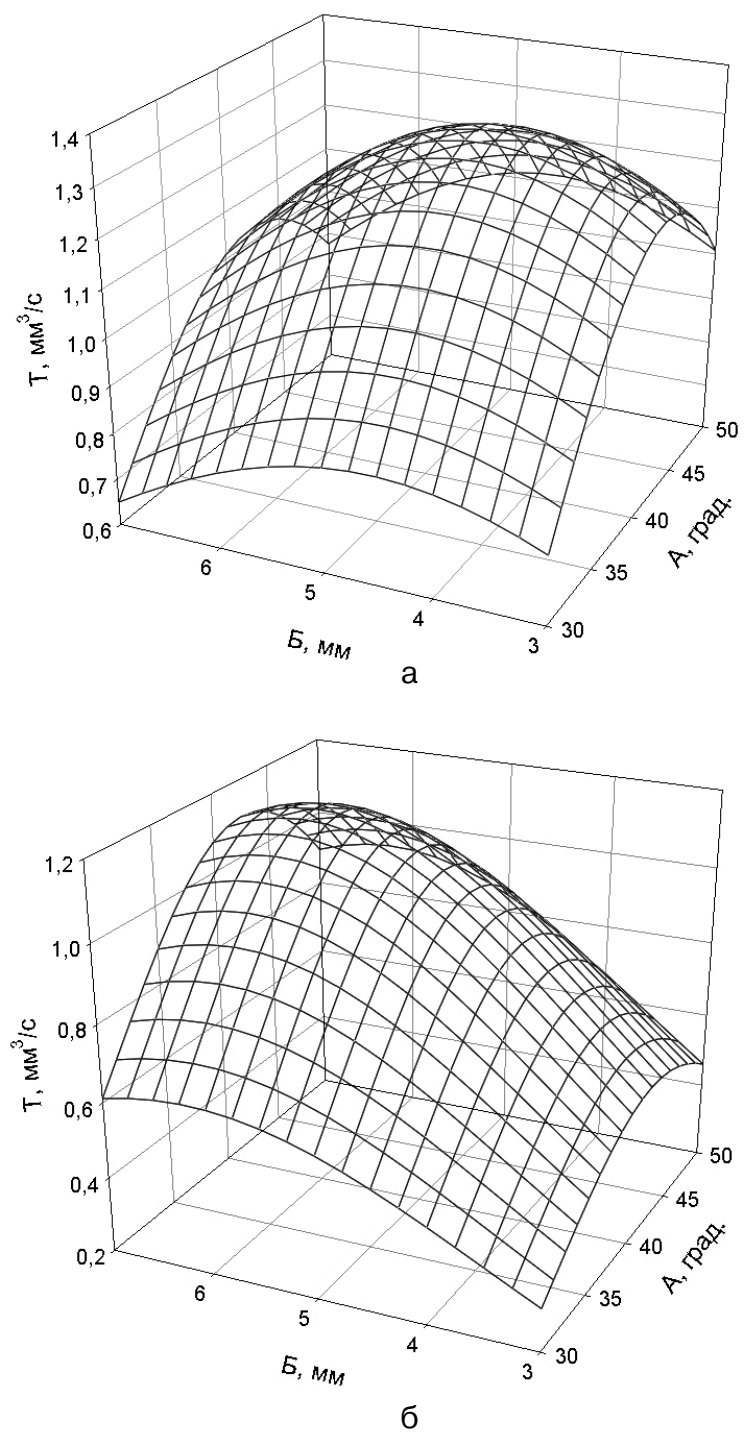

Рис. 2. Залежність продуктивності (Т) від геометрії кутів утворюючих сопла (А) для різних положень підкладки (Б): а - масова витрата порошку 0,3 г/с, швидкість переміщення підкладки 2 мм/с, б - масова витрата порошку 0,4 г/с, швидкість переміщення підкладки 3 мм/с

положення підкладки щодо зрізу сопла 3 мм, це пояснюється головним чином низькими показниками дисперсної фази в зоні лазерної обробки, за рахунок віддалення положення підкладки від «фокусу» газо- порошкового струменя. $\mathrm{Ha}$ рис. 3, а-в як приклад представлені фотографії морфологічної структури сплавлених компонентів порошкового матеріалу для різної геометрії кутів утворюють сопла. 

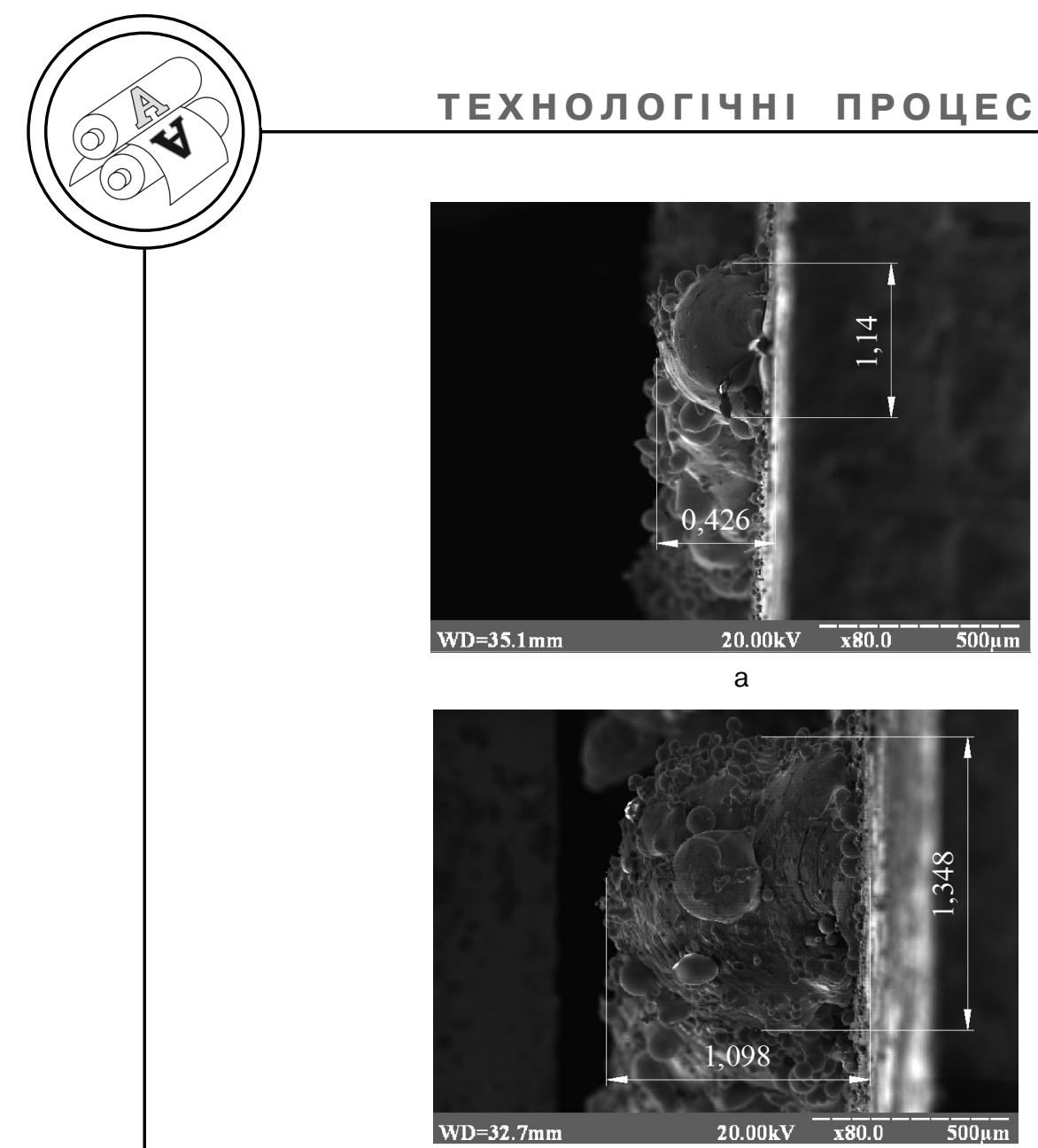

б

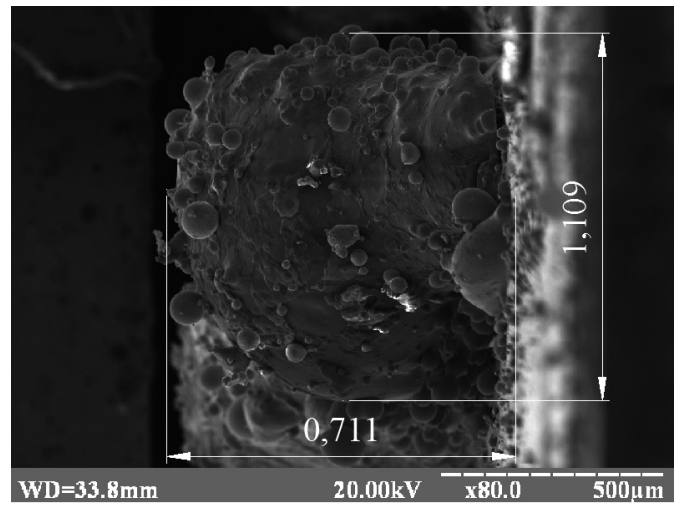

B

Рис. 3. Морфологічна структура сплавлених компонентів з реальними розмірами висоти і ширини при восьмидесятикратному оптичному збільшенні: a - геометрія кутів утворюючих сопла $30^{\circ}$, масова витрата порошку 0,2 г/с, швидкість переміщення підкладки 3 мм/с, положення підкладки щодо зрізу сопла 7 мм, б - геометрія кутів утворюють сопла $40^{\circ}$, масова витрата порошку 0,3 г/с, швидкість переміщення підкладки 1 мм/с,

положення підкладки щодо зрізу сопла 5 мм, в - геометрія кутів

утворюючих сопла $50^{\circ}$, масова витрата порошку 0,2 г/с, швидкість переміщення підкладки 2 мм/с, положення підкладки щодо зрізу сопла 7 мм 


\section{Висновки}

1. Отримано математичну модель продуктивності процесу лазерного сплавлення порошкової композиції ПГСР-3, яка в подальшому може використовуватися в якості розрахунку керованих впливів спрямованих на зростання продуктивності майбутніх виробів.
2. Підтверджено адекватність теоретичних розрахунків і можливості використання математичних моделей процесу лазерного сплавлення порошкового матеріалу для подальшого використання їх при реалізації технології лазерного сплавлення порошкового матеріалу.

1. M. Alimardani. On the 3D modeling of geometrical formation in laser solid freeform fabrication process [Електронний ресурс] : Proceedings of International Congress «ICALEO'2006», Scottsdale, USA, Oct. 2006, LIA. 1 електрон. опт. диск (CD-ROM). - Систем. вимоги : Pentium; 32 Mb RAM; Windows 95, 98, 2000, ХР. - Назва з контейнера. 2. Magdi Azer. Laser net shape manufacturing using an adaptive toolpath deposition method. [Електронний ресурс] : Proceedings of International Congress «ICALEO'2007», Orlando, USA, Oct. 2007, LIA. - 1 електрон. опт. диск (CD-ROM). - Систем. вимоги : Pentium; 32 Mb RAM; Windows 95, 98, 2000, XP. - Назва з контейнера. 3. F. Lusquicos. Rapid fabrication of electrical discharge machining (EDM) electrodes by laser surface cladding [Електронний pecypc] : Proceedings of International Congress «ICALEO'2007», Orlando, USA, Oct. 2007, LIA. - 1 електрон. опт. диск (CD-ROM). - Систем. вимоги: Pentium; 32 Mb RAM; Windows 95, 98, 2000, ХР. - Назва 3 контейнера. 4. М. Alimardani. A coupled time-dependent numerical simulation on temperature and stress fields in laser solid freeform fabrication process [Електронний ресурс] : Proceedings of International Congress «ICALEO'2007», Orlando, USA, Oct. 2007, LIA. - 1 електрон. опт. диск (CD-ROM). - Систем. вимоги : Pentium; 32 Mb RAM; Windows 95, 98, 2000, ХР. - Назва з контейнера. 5. Г. В. Самсонов. Физико-химические свойства элементов [Текст] / Г. В. Самсонов, А. Л. Бурыкина, Ю. М. Горячев и др. - К. : Наукова думка, 1965. - 806 с. 6. А. J. Pinkerton. A Comparative Study of Multiple Layer Laser Deposition using Water and Gas Atomised 316L Stainless Steel Powders [Електронний ресурс] : Proceedings of International Congress «ICALEO'2002», Scottsdale, USA, Oct. 2002, LIA. 1 електрон. опт. диск (CD-ROM). - Систем. вимоги : Pentium; 32 Mb RAM; Windows 95, 98, 2000, XP. - Назва $з$ контейнера. 7. M. Kutsuna. Clack behavior and microstructure of clad layer in laser cladding of stellite 6 and WC Powder [Електронний ресурс] : Proceedings of International Congress «ICALEO'2004», Oct. 4-7, 2004, San Francisco, California, USA, LIA. 1 електрон. опт. диск (CD-ROM). - Систем. вимоги : Pentium; 32 Mb RAM; Windows 95, 98, 2000, XP. - Назва з контейнера. 8. J Mei. Finite Element Analysis of the Thermal Behaviour and Its Implications to the Microstructure of Direct Laser Fabricated Samples (905) [Електронний ресурс] : Proceedings of International Congress «ICALEO'2003», Jacksonville, USA, Oct. 2003, LIA. - 1 електрон. опт. диск (CD-ROM). - Систем. вимоги : Pentium; 
$32 \mathrm{Mb}$ RAM; Windows 95, 98, 2000, XP. - Назва 3 контейнера. 9. A. J. Pinkerton. A Verified model of laser direct metal deposition using an analytical enthalpy balance method [Електронний ресурс] : Proceedings of International Congress «ICALEO'2007», Orlando, USA, Oct. 2007, LIA. 1 електрон. опт. диск (CD-ROM). - Систем. вимоги : Pentium; 32 Mb RAM; Windows 95, 98, 2000, XР. - Назва з контейнера. 10. Новик Ф. С. Оптимизация процессов технологии металлов методами планирования экспериментов [Текст] / Ф. С. Новик, Я. Б. Арсов. - М. : Наука, 1980. $304 \mathrm{c}$.

1. M. Alimardani. On the $3 D$ modeling of geometrical formation in laser solid freeform fabrication process [Elektronnyi resurs] : Proceedings of International Congress «ICALEO'2006», Scottsdale, USA, Oct. 2006, LIA. 1 elektron. opt. dysk (CD-ROM). - System. vymohy : Pentium; 32 Mb RAM; Windows 95, 98, 2000, XP. - Nazva z konteinera. 2. Magdi Azer. Laser net shape manufacturing using an adaptive toolpath deposition method. [Elektronnyi resurs] : Proceedings of International Congress «ICALEO'2007», Orlando, USA, Oct. 2007, LIA. - 1 elektron. opt. dysk (CD-ROM). - System. vymohy : Pentium; 32 Mb RAM; Windows 95, 98, 2000, XP. - Nazva z konteinera. 3. F. Lusquisos. Rapid fabrication of electrical discharge machining (EDM) electrodes by laser surface cladding [Elektronnyi resurs] : Proceedings of International Congress «ICALEO’2007», Orlando, USA, Oct. 2007, LIA. 1 elektron. opt. dysk (CD-ROM). - System. vymohy : Pentium; 32 Mb RAM; Windows 95, 98, 2000, XP. - Nazva z konteinera. 4. M. Alimardani. A coupled time-dependent numerical simulation on temperature and stress fields in laser solid freeform fabrication process [Elektronnyi resurs] : Proceedings of International Congress «ICALEO'2007», Orlando, USA, Oct. 2007, LIA. 1 elektron. opt. dysk (CD-ROM). - System. vymohy : Pentium; 32 Mb RAM; Windows 95, 98, 2000, XP. - Nazva z konteinera. 5. G. V. Samsonov. Fizikohimicheskie svojstva jelementov [Tekst] / G. V. Samsonov, A. L. Burykina, Ju. M. Gorjachev i dr. - K. : Naukova dumka, 1965. - 806 s. 6. A. J. Pinkerton. A Comparative Study of Multiple Layer Laser Deposition using Water and Gas Atomised 316L Stainless Steel Powders [Elektronnyi resurs] : Proceedings of International Congress «ICALEO'2002», Scottsdale, USA, Oct. 2002, LIA. 1 elektron. opt. dysk (CD-ROM). - System. vymohy : Pentium; 32 Mb RAM; Windows 95, 98, 2000, XP. - Nazva z konteinera. 7. M. Kutsuna. Clack behavior and microstructure of clad layer in laser cladding of stellite 6 and WC Powder [Elektronnyi resurs] : Proceedings of International Congress «ICALEO'2004», Oct. 4-7, 2004, San Francisco, California, USA, LIA. - 1 elektron. opt. dysk (CD-ROM). - System. vymohy : Pentium; 32 Mb RAM; Windows 95, 98, 2000, XP. - Nazva z konteinera. 8. J Mei. Finite Element Analysis of the Thermal Behaviour and Its Implications to the Microstructure of Direct Laser Fabricated Samples (905) [Elektronnyi resurs] : Proceedings of International Congress «ICALEO'2003», Jacksonville, USA, Oct. 2003, LIA. 1 elektron. opt. dysk (CD-ROM). - System. vymohy : Pentium; $32 \mathrm{Mb}$ RAM; Windows 95, 98, 2000, XP. - Nazva z konteinera. 9. A. J. Pinkerton. A Verified 
model of laser direct metal deposition using an analytical enthalpy balance method [Elektronnyi resurs] : Proceedings of International Congress «ICALEO'2007», Orlando, USA, Oct. 2007, LIA. - 1 elektron. opt. dysk (CD-ROM). - System. vymohy : Pentium; 32 Mb RAM; Windows 95, 98, 2000, XP. - Nazva z konteinera. 10. Novik F. S. Optimizacija processov tehnologii metallov metodami planirovanija jeksperimentov [Tekst] / F. S. Novik, Ja. B. Arsov. - M. : Nauka, 1980. - 304 s.

Рецензент - М. І. Анякін, д.т.н., c.н.c., НТУУ «КПI»

Надійшла до редакції 24.09.13 